\title{
Analysis of contraceptive behavior of female athletes of reproductive age
}

\section{Bugaevsky KA}

Department of Medical and Biological Foundations of Sports and Physical Rehabilitation, The Petro Mohyla Black Sea State University, Nilolaev, Ukraine

Corresponding author: Konstantin Anatolyevich Bugaevsky, Assistant Professor, Department of Medical and Biological Foundations of Sports and Physical Rehabilitation, The Petro Mohyla Black Sea State University, Nilolaev, Ukraine

Received date: November 19, 2021; Accepted date: December 28, 2021; Published date: January 05, 2021

Citation: Konstantin A. Bugaevsky (2022). Analysis of contraceptive behavior of female athletes of reproductive age. J. Women Health Care and Issues. 5(1); DOI:10.31579/2642-9756/096

Copyright: (C) 2022 Konstantin Anatolyevich Bugaevsky, This is an open access article distributed under the Creative Commons Attribution License, which permits unrestricted use, distribution, and reproduction in any medium, provided the original work is properly cited.

\section{Abstract}

The article presents the materials of a large-scale study devoted to the study of the contraceptive behavior of female athletes of reproductive age, representing different sports. It has been established that the most commonly used types of contraception, in all age categories, are: interrupted intercourse, spermicides, barrier contraception (male condoms), hormonal patches. The most rarely used are hormonal contraception (singlephase and three-phase combined oral contraceptives) and intrauterine contraception. It has been established that the choice of a particular type of contraception among athletes is determined by such leading factors as sexual activity, frequency of sexual contacts, the number of sexual partners, the presence or absence of a family and marriage.

Keywords: sportswomen; reproductive age; contraceptive behavior; type of contraception

\section{Abbreviation}

IUD - intrauterine devices

COCs - combined oral contraceptives

STDs / STIs - Sexually Transmitted Diseases / Infections

\section{Introduction}

Women's sports and women's health are two important issues that are very relevant and not fully understood. The multifaceted impact of sports on the female body is very ambiguous and polar! There are many supporters of women's professional sports, and no fewer opponents. Recently, there are studies that negatively assess the initiation of sports in childhood and, in particular, before the girls have their first menstruation, or menarche. Also, the issue of the use of different types of contraceptives by athletes of reproductive age has not been fully investigated. This is especially true for the use of hormonal contraception by young female athletes. How does it affect sports performance and the state of her reproductive health and the endocrine system. The question of what is the use of contraception for an athlete is not fully understood - benefit or harm. Also, additional research is required by the question of the reproductive behavior of athletes, the presence and frequency of spontaneous and artificial terminations of pregnancy, the impact of childbirth on a sports career. This article will analyze the long-term study of the characteristics of individual contraception in athletes of reproductive age who are professionally involved in a number of sports.

Aim of the work: to present the analysis of the obtained results of the study, with the definition of practical conclusions, on the use of contraception by athletes of reproductive age, going in for different kinds of sports.

\section{Material and methods}

To conduct this study, an exclusive author's anonymous questionnaire was used (author-Dr. Bugaevsky K.A., 2018@), containing 28 questions regarding the individual contraceptive and reproductive behavior of the studied athletes. Also, to clarify a number of questions necessary for the study, the extended interviewing method was additionally applied. To compare the results of the study, the author studied the available and available sources of information on the issue under study.

In carrying out this research work, we used the method of in-depth literary-critical analysis of available scientific sources of information on the issue under study, using reference books, encyclopedias, catalogs, specialized periodicals, and Internet resources.

This study involved 1687 female athletes, aged 17 to 29 years old, actively involved in sports, sexually active and using various types of contraception to prevent unwanted pregnancies. All athletes who took part in the study, gave their voluntary consent to participate in it. 


\section{Result and discussion}

After completing the filling of anonymous questionnaires, and conducting, if necessary, extended interviews with athletes, the following results were established, of their individual use of contraceptives, which are shown in Table.

\begin{tabular}{|l|l|l|}
\hline Indicator name & Group aged 17 to 23 (n=1174) & Group aged 23 to 29 (n=513) \\
\hline Type / method of contraception & $1174(100 \%)$ sportswomen & $319(62.18 \%)$ sportswomen \\
\hline Naitus interruptus & Not used & Not used \\
\hline Barrier Contraception / Male Condom & $1174(100 \%)$ sportswomen & $223(43.47 \%)$ sportswomen \\
\hline Spermocides & $1095(93.27 \%)$ sportswomen & $91(17.74 \%)$ sportswomen \\
\hline Hormonal plaster & $1174(100 \%)$ sportswomen & $11(2.14 \%)$ sportswomen \\
\hline Outdoor Hormonal Ring & $212(18.06 \%)$ sportswomen & Not used \\
\hline Combined oral contraceptives & $34(2.9 \%)$ sportswomen & Not used \\
\hline Intrauterine contraception & Not used & $481(93.76 \%)$ sportswomen \\
\hline Injectable hormonal contraceptives & Not used & Not used \\
\hline
\end{tabular}

Table: Features of the use of different types of contraception by female athletes $(n=1687)$

An analysis of the results of anonymous questionnaire, as well as additional extended interviewing showed that no athlete was used by almost no type of natural, natural contraception, motivating this complexity of use (for example, everyday measurement of the rectal temperature and temperature chart) and the subjectivity of the results obtained ( The state of the cervical mucus). One of the most popular types of contraception, in both age groups is interrupted sexual intercourse and the use of a male condom. Further, among the most "popular", among the athletes of both under study groups, the use of percutaneous hormonal plasters of different pharmaceutical firms and, also, of different types of spermicidal agents (vaginal tablets, ointments, sprays) were allocated [110].

Female athletes determine the election of these contraceptives, their simplicity and use for a particular, single sexual intercourse, or a short stage of time (within 1-2 days). Very little, extremely rare, and then, according to the testimony of the gynecologist, often with the secondary goal), most often with therapeutic and cosmetology, single-phase and, in particular, three-phase combined oral contraceptives are applied. Twophase COC's did not apply to any female athletes. Additional interviewing athletes showed that interrupted sexual intercourse, condom, patches and sperms, most often use young and young athletes who have unresolved, not stable sex life, rare and episodic sexual contacts, as well as several sexual partners [1-10]. At the same time - the number of sexual partners can be from two to 10-12. Most often, unfortunately, these are random sexual partners. A stable partner, alas, is not a frequent phenomenon, which is associated with the specifics of professional activities of female athletes, frequency and intensity of training, frequent trips for competitions, etc. At the same time, sex contacts can be quite frequent - from two or more to fall, sometimes every day! At the older group, the frequency of sex contacts is reduced, like the number of random sex contacts. Here the presence of a stable partner is dominated, sometimes two, and even in married female athletes [1-10].

Further, among the most "popular", among the female athletes of both under study groups, the use of percutaneous hormonal plasters of different pharmaceutical firms and, also, of different types of spermicidal agents (vaginal tablets, ointments, sprays) were allocated.
As for the use of intrauterine contraception, the married athletes of older age leading here (from 25 to 29 years old), with a stable sexual life, often already having from 1 to 2 children. Preference is given to an intrauterine hormone-containing complex "Mirena" $®$, or ordinary intrauterine equipment, with copper or silver [1;2; 7-10].

Naturally, younger and unmarried athletes choose the means of barrier contraception, due to simple use, the rapid start of action and protection time sufficient for 1-2 sexual acts. In addition, spermicides not only reliably protect against STDs, but also effectively prevent the onset of unwanted pregnancy, which is a fairly weighty argument for athletes who do not have a permanent sexual partner. A barrier contraceptive device such as a female condom received a $100 \%$ negative assessment, both because of the "difficulty of insertion" and the constraint / aesthetic inconvenience of using it in the presence of your sexual partner, as well as constant anxiety about whether it has moved into the vagina and whether it protects he's a boyfriend. The drug of choice can be called transdermal hormone-containing patches such as "EVRA®" and the like. Sufficiently high reliability, ease of use, quick onset of action, the ability to use, in almost any situation, makes this contraceptive indispensable in the issue of reliable contraception in the athletes we studied $[1 ; 2 ; 7-10]$.

A slightly different motivation for athletes who have one permanent sexual partner and / or are married, as well as those who have already given birth and have one or more children. Here, in the first place is the reliability of the contraceptive, its effectiveness and ease of use. Unfortunately, in this case, COCs are not quite suitable, first of all, because of the strict obligation of constant intake, the danger of missing one or two tablets in a row, as well as the fear of possible complications when taking them. The use of the intrauterine hormonal releasing system "Mirena ${ }^{\circledR}$ " and similar means is very limited due to the high cost of this means in Ukraine and its frequent expulsions in a number of sports, such as weightlifting, kettlebell lifting, triathlon, and a number of contact martial arts. Injectable hormonal contraceptives, such as «DepoProvera" ${ }^{\circledR}$, have never been used by any of the athletes we examined [1; $2 ; 7-10]$.

Such a contraceptive as the intravaginal hormone-containing ring "NOVA-RING®" did not find active supporters in special age groups of 
female athletes $[3 ; 4 ; 8]$. In the first place comes the subjective sensation of a foreign object in the vagina, and the fear of its prolapse from the vagina, both during intercourse and during active sports, including training and competition. Also, it should be noted that younger and sexually active athletes often use combinations of contraceptives condoms and spermicides, hormonal patches and spermicides, believing that in this way, they will be more reliably protected from both unwanted pregnancy and sexually transmitted diseases [1-10].

\section{Conclusion}

1. Sportswomen of all studied age groups use a variety of contraceptives quite actively.

2. Younger female athletes, in their sexual practice, prefer hormonal patches, male condoms and spermicidal agents, considering them to be more reliable means of protection against unwanted pregnancies and sexually transmitted infections.

3. Female athletes in both groups never used biphasic oral contraceptives, injectable hormonal contraceptives, and natural family planning methods.

4. In addition, young female athletes have never used a female condom and intrauterine contraception, as well as pill combined oral contraceptives, citing aesthetic inconvenience and complexity of use.

5. Older athletes, primarily having one stable sexual partner and being married, prefer more reliable intrauterine contraception, with the longest possible protection against unwanted pregnancy.

The author notes the absence of any conflict of interest.

\section{References}

1. Anoprienko SV Modern methods of contraception. SPb.: Phoenix. 2008. $176 \mathrm{p}$.

2. Korkhov VV Medical aspects of the use of contraceptives drugs. SPb: Special literature. 2006. 198 p.

3. Guidelines for contraception / ed. prof. VN Prilepskaya. - 2nd ed., rev. and add. - M .: MEDpress-inform. 2011 . 448 p.

4. Stenyaeva NN, Kuzemin A. Female sexual function and hormonal contraception. // Gynecology. 2013. 4:5-39.

5. Yurchuk OA, Khlybova SV, Tsirkin V.I. Reproductive function of women engaged in various sports. The successes of modern natural science. 2006. 9:91-93.

6. Burrows M., Peters C.E. The influence of oral contraceptives on athletic performance in female athletes. Sports Med. 2007; 37:557-574.

7. Bennell K., White S., Crossley K.: The oral contraceptive pill: a revolution for sportswomen? Br J Sports Med 1999 Aug; 33(4):231-238.

8. Frankovich RJ, Lebrun CM. Menstrual Cycle, Contraception, and Performance. Clin Sports Med 2000 Apr; 19 (2): 251-271

9. Iyer V., Farquhar C., Jepson R.Oral contraceptive pills for heavy menstrual bleeding (Cochrane review) / In: The Cochrane Library, Issue 2, 2004. - Chichester, UK.

10. Lebrun CM, Petit MA, McKenzie DC, Taunton JE, Prior JC Decreased maximal aerobic capacity with use of a triphasic oral contraceptive in highly active women: a randomised controlled trial. Br J Sports Med 2003;37:315-320.

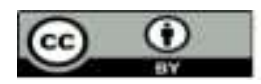

This work is licensed under Creative Commons Attribution 4.0 License

To Submit Your Article Click Here:

Submit Manuscript
Ready to submit your research? Choose Auctores and benefit from:

$>$ fast, convenient online submission

$>$ rigorous peer review by experienced research in your field

$>$ rapid publication on acceptance

$>$ authors retain copyrights

$>$ unique DOI for all articles

$>$ immediate, unrestricted online access

At Auctores, research is always in progress.

Learn more https://auctoresonline.org/journals/women-health-care-and-issues- 